\title{
Constraints on the presence of post-perovskite in Earth's lowermost mantle from tomographic-geodynamic model comparisons
}

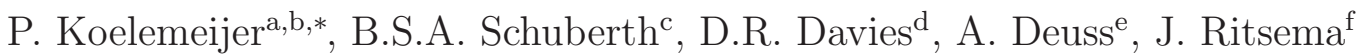 \\ ${ }^{a}$ University College Oxford, Department of Earth Sciences, University of Oxford, Oxford, \\ United Kingdom \\ ${ }^{b}$ Institute of Geophysics, Department of Earth Sciences, ETH Zürich, Zurich, \\ Switzerland \\ ${ }^{c}$ Ludwig-Maximilians-Universität München, Munich, Germany \\ ${ }^{d}$ Australian National University, Canberra, Australia \\ ${ }^{e}$ Department of Earth Sciences, Utrecht University, Utrecht, The Netherlands \\ ${ }^{f}$ Department of Earth and Environmental Sciences, University of Michigan, Ann Arbor, \\ USA
}

\begin{abstract}
Lower mantle tomography models consistently feature an increase in the ratio of shear-wave velocity $\left(V_{S}\right)$ to compressional-wave velocity $\left(V_{P}\right)$ variations and a negative correlation between shear-wave and bulk-sound velocity $\left(V_{C}\right)$ variations. These seismic characteristics, also observed in the recent SP12RTS model, have been interpreted to be indicative of large-scale chemical variations. Other explanations, such as the lower mantle post-perovskite $(\mathrm{pPv})$ phase, which would not require chemical heterogeneity, have been explored less. Constraining the origin of these seismic features is important, as geodynamic simulations predict a fundamentally different style of mantle convection under both scenarios. Here, we investigate to what extent the presence of $\mathrm{pPv}$ explains the observed high $V_{S} / V_{P}$ ratios and negative $V_{S^{-}} V_{C}$
\end{abstract}

*paula.koelemeijer@univ.ox.ac.uk 
correlation globally. We compare the statistical properties of SP12RTS with the statistics of synthetic tomography models, derived from both thermal and thermochemical models of 3-D global mantle convection. We convert the temperature fields of these models into seismic velocity structures using mineral physics lookup tables with and without $\mathrm{pPv}$. We account for the limited tomographic resolution of SP12RTS using its resolution operator for both $V_{S}$ and $V_{P}$ structures. This allows for direct comparisons of the resulting velocity ratios and correlations. Although the tomographic filtering significantly affects the synthetic tomography images, we demonstrate that the effect of $\mathrm{pPv}$ remains evident in the ratios and correlations of seismic velocities. We find that lateral variations in the presence of $\mathrm{pPv}$ have a dominant influence on the $V_{S} / V_{P}$ ratio and $V_{S^{-}} V_{C}$ correlation, which are thus unsuitable measures to constrain the presence of large-scale chemical variations in the lowermost mantle. To explain the decrease in the $V_{S} / V_{P}$ ratio of SP12RTS close to the CMB, our results favour a pPv-bearing CMB region, which has implications for the stability field of $\mathrm{pPv}$ in the Earth's mantle. Keywords: Seismic tomography, Tomographic filtering, Composition of the mantle, Geodynamic modelling, Mineral physics

\section{Introduction}

Tomographic models typically display an increase in the ratio of shear3 wave velocity variations $\left(\operatorname{dnn} V_{S}=\delta V_{\mathrm{S}} / V_{\mathrm{S}}\right)$ to compressional-wave velocity 4 variations $\left(\operatorname{dn} V_{P}\right)$ up to values of $2.5-3.5$ in the lowermost mantle, ac5 companied by a strong negative correlation between shear-wave and bulk6 sound velocity variations $\left(\operatorname{dln} V_{C}\right)$ (e.g. Su and Dziewonski, 1997; Ishii and 
7 Tromp, 1999; Masters et al., 2000; Della Mora et al., 2011; Koelemeijer et al., 8 2016). The depth extent of these seismic features varies (Fig. 1). Models 9 based on body-wave data typically show high ratios throughout the lower 10 mantle, whereas models based on longer period data feature lower ratios. 11 Model SP12RTS contains a marked decrease in the ratio near the core-mantle boundary (CMB), a robust feature due to the incorporation of CMB Stoneley mode data (Koelemeijer et al., 2016).

[Fig. 1 about here.]

Traditionally, observations of a high ratio of $\operatorname{d} \ln V_{S}$ over $\operatorname{dn} V_{P}$ (from hereon termed $S / P$ ratio) and a negative correlation between $\operatorname{dn} V_{S}$ and $\mathrm{d} \ln V_{C}$ (from hereon termed $S$-C correlation) have been interpreted as evidence for compositional heterogeneity (e.g. Su and Dziewonski, 1997; Masters et al., 2000; Moulik and Ekström, 2016), as purely thermal effects (in the absence of temperature-dependent phase changes) only produce a $\mathrm{S} / \mathrm{P}$ ratio of up to $\sim 2.5$ (Karato and Karki, 2001). Specifically, two large-lowvelocity provinces (LLVPs) underneath the Pacific and Africa, which cover $\sim 25$ percent of the core surface, are thought to be chemically distinct, as these feature the largest increase in the $\mathrm{S} / \mathrm{P}$ ratio, have a pronounced negative S-C correlation (Masters et al., 2000; Koelemeijer et al., 2016) and show a large deviation from purely thermal velocity variations (Simmons et al., 2010; Tesoniero et al., 2016). In the past, this interpretation has been corroborated by normal-mode density models that indicated that the LLVPs have a higher-than-average density (Ishii and Tromp, 1999; Trampert et al., 2004). However, recent studies have found both dense (Moulik and Ekström, 2016; Lau et al., 2017) and light LLVPs (Koelemeijer et al., 2017). 
Determining the origin of the large-scale LLVPs is important, as isochemical and thermochemical convection models predict distinct thermochemical evolutionary pathways, different geochemical residence times, a contrasting distribution and magnitude of CMB heat flow, and, hence, models of outer core convection.

Before observations of a high $\mathrm{S} / \mathrm{P}$ ratio and negative $\mathrm{S}-\mathrm{C}$ correlation can be interpreted as solely due to chemical heterogeneity, other mechanisms need to be considered. As suggested in the past (Tsuchiya et al., 2004; Wookey et al., 2005), the lower mantle post-perovskite phase (pPv) also provides an possible explanation for these seismic features without the need for large-scale chemical variations. An increase in $V_{S}$ and a decrease in $V_{P}$ accompanies the phase transition from bridgmanite (brg) to pPv (e.g. Murakami et al., 2004; Oganov and Ono, 2004; Tsuchiya et al., 2004), resulting in an increased S/P ratio and a negative $\mathrm{S}-\mathrm{C}$ correlation. In addition, the presence of a phase transition introduces artefacts in radially-averaged depth profiles of seismic velocities and their ratios (Styles et al., 2011). Although, in principle, the properties of $\mathrm{pPv}$ thus explain seismic characteristics of global tomography models (Davies et al., 2012, 2015), its stability field is composition-dependent and remains poorly constrained by mineral physics (Cobden et al., 2014). In addition, it has not been investigated yet whether: (i) the occurrence of pPv is expected to be widespread enough to influence radially-averaged seismic properties; (ii) the effect of $\mathrm{pPv}$ is observable in large-scale global tomography models; and thus whether (iii) global tomography can be used to constrain its stability field.

Here, we aim to establish whether the presence of $\mathrm{pPv}$ or chemical het- 
57 erogeneity is the dominant factor in explaining the globally observed high $\mathrm{S} / \mathrm{P}$ ratio and negative $\mathrm{S}-\mathrm{C}$ correlation in the lowermost mantle. In addition, we investigate whether global tomography can provide insights into the stability field of post-perovskite. To this end, we study the seismic properties of geodynamic models with and without $\mathrm{pPv}$, and compare these to seismic tomography models. As in previous studies (Schuberth et al., 2009a; Davies et al., 2012), we ensure that our comparisons are meaningful, especially in terms of the amplitudes, by utilising a tomographic resolution operator (Ritsema et al., 2007). Although studies have filtered $V_{S}$ structures in the past, using for example the resolution operator of S40RTS (Ritsema et al., 2011), joint filters for $V_{S}$ and $V_{P}$ structures are not readily available. Here, we use the resolution operator of SP12RTS (Koelemeijer et al., 2016), which filters both $\operatorname{dn} V_{S}$ and $\operatorname{dn} V_{P}$ structures simultaneously and has an improved resolution close to the CMB due to the inclusion of Stoneley mode data. Therefore, comparisons of SP12RTS with filtered geodynamic models enable us to investigate the origin of the high $\mathrm{S} / \mathrm{P}$ ratio near $2500 \mathrm{~km}$ depth, its decrease towards the $\mathrm{CMB}$ and the negative $\mathrm{S}-\mathrm{C}$ correlation in the lowermost mantle. This paper is organised as follows: In Section 2, we provide a brief description of model SP12RTS and the geodynamic models used in this study, before introducing the SP12RTS tomographic resolution operator (Section 2.3). Subsequently, we discuss the effects of reparameterisation and tomographic filtering on synthetic tomography models in Section 3, demonstrating that the effect of $\mathrm{pPv}$ remains evident throughout these processing steps. In Section 4 we compare SP12RTS with the geodynamic models, discussing their properties and the important effects of data weighting and the Clapeyron 
slope in the tomographic inversions. These comparisons indicate that $\mathrm{pPv}$ plays a dominant role in explaining lowermost mantle characteristics of global seismic tomography models, even within the LLVPs. Finally, in Section 5 we discuss the implications of our results in light of the current state of knowledge in mineral physics, showing that tomographic-geodynamic comparisons can potentially be used to constrain the stability field of $\mathrm{pPv}$.

\section{Model specifications and resolution operator}

We briefly review model SP12RTS and the geodynamic models explored in this study. We refer the reader to Koelemeijer et al. (2016) for further details on model SP12RTS and to Schuberth et al. (2009b) and Davies et al. (2012) for a more extensive discussion of the geodynamic modelling and mineral physics conversions.

\subsection{Seismic model SP12RTS}

SP12RTS is a whole-mantle, long-wavelength model of shear-wave and compressional-wave velocity variations, obtained using the same inversion procedure as S-wave velocity model S40RTS (Ritsema et al., 2011). To optimise data coverage, normal-mode splitting function measurements, Rayleigh wave phase-velocity measurements and teleseismic body-wave traveltimes were combined, with varying weighting factors between the three data sets. Compared to S40RTS, P-wave traveltime data were added and the normalmode splitting function data set was significantly increased (143 modes instead of 49). By including 33 new modes sensitive to $V_{P}$ variations, as well as 9 CMB Stoneley modes with an unique sensitivity to the lowermost mantle (Koelemeijer et al., 2013), P-wave velocity variations were independently 
constrained in the inversion. The model was parameterised laterally in spherical harmonics up to angular order 12, limiting us to consider large-scale structure only.

Fig. 2 shows the velocity structure of SP12RTS in the lowermost mantle. The long-wavelength $V_{S}$ structure is practically identical to that of S40RTS, and SP12RTS contains many features observed in other tomographic models. Large regions of low shear- and compressional-wave velocities (LLVPs) exist underneath the Pacific and Africa, increasing in strength towards the CMB. The LLVP under the Pacific is more circular, whereas the African LLVP is elongated in the North-South direction, and both are surrounded by a ring of higher velocities. $V_{S}$ amplitudes increase continuously with depth, whereas $V_{P}$ variations only increase from $\sim 2500 \mathrm{~km}$ depth. However, their geographic patterns are strongly correlated at all depths. The $V_{C}$ variations, constructed using $\operatorname{dnn} V_{S}$ and $\operatorname{d} \ln V_{P}$ following the method of Masters et al. (2000), are negatively correlated with $V_{S}$ variations, both within and outside the LLVPs. The negative $\mathrm{S}-\mathrm{C}$ correlation and $\mathrm{S} / \mathrm{P}$ ratio peak at a depth of $2500 \mathrm{~km}$ before decreasing towards the CMB (Fig. 1). Although such a decrease had been observed previously (Romanowicz, 2001; Della Mora et al., 2011), it was generally attributed to poor data coverage near the CMB. However, in case of SP12RTS, Koelemeijer et al. (2016) showed that this is a robust feature due to the incorporation of CMB Stoneley modes.

[Fig. 2 about here.]

\subsection{Geodynamic models}

We use high-resolution global mantle circulation models similar to those presented in Schuberth et al. (2009b) and Davies et al. (2012). We generate 
temperature and compositional fields using a modified and benchmarked version of the spherical mantle convection code TERRA (Baumgardner, 1985; Davies et al., 2013), which solves for the conservation equations of mass, momentum and energy at infinite Prandtl number (i.e. no inertial forces). We prescribe isothermal conditions at the surface (300 K) and CMB (4000 K). We specify a free slip boundary condition at the CMB, while we prescribe surface velocities according to 200 Myr of plate motion history (Seton et al., 2012), at discrete 1 Myr intervals. A fine discretisation $(\sim 25 \mathrm{~km}$ cells, resulting in about 80 million grid points) allows us to simulate mantle flow at Earthlike convective vigour, which is essential for generating synthetic structures that are comparable to seismic observations of Earth's present-day mantle. Our models include internal heating in the mantle, compressibility and a temperature-depth dependent viscosity. The Supplementary Material contains further details on these parameters and the model initiation procedure, with key model parameters listed in Supplementary Table S1.

Similarly to Davies et al. (2012), we focus on two end-member scenarios for describing temperature variations within the mantle: (i) a purely thermal model with no chemical heterogeneity ('TH' models from hereon); and (ii) a thermochemical 'pile' model, where chemically distinct material focuses into large-scale structures in the lowermost mantle ('TC' models from hereon). We convert modelled temperature, pressure and compositional fields into elastic parameters using lookup tables generated using a thermodynamic mineralogical model for a simplified six-component system of mantle composition (Stixrude and Lithgow-Bertelloni, 2011). We opt to use such a self-consistent mineralogical model, where the thermodynamics of the sys- 
tem dictate the stability field of $\mathrm{pPv}$ and thus its Clapeyron slope, instead of assuming a constant Clapeyron slope (see Supplementary Fig. S1 and Supplementary Material). This way, we incorporate the non-linear pressure and temperature dependence of material properties and account for non-linear thermodynamic effects on phase transitions.

We perform the conversion using two versions of the lookup tables for each chemical composition, one including and the other excluding $\mathrm{pPv}$ from the database. Hence, we obtain four synthetic tomography models: models TH-pPv and TC-pPv where $\mathrm{pPv}$ is included, and models TH-nopPv and TC-nopPv where $\mathrm{pPv}_{\mathrm{v}}$ is not present in the lowermost mantle. For TH-pPv models, we also test the influence of the assumed Clapeyron slope using extrapolated (i.e. not physically constrained) mineral physics tables, described in more detail in the Supplementary Material. In the conversion, we assume a pyrolitic mantle composition for the TH models, whereas TC models contain an additional basalt component, which comprises $\sim 3 \%$ of the mantle's volume (see Supplementary Table S2). We do not include the dynamic effects of the post-perovskite transition in the geodynamic simulations themselves, only at the conversion stage to seismic velocities. However, as we limit ourselves to the interpretation of large-scale statistical properties, we do not expect our results to change significantly (see Supplementary Material).

[Fig. 3 about here.]

Fig. 3 illustrates present-day snapshots of the temperature field, $V_{S}$ structure and $\mathrm{pPv}$ occurrence in the geodynamic models in the lowermost mantle. Remnants of old slabs are visible above the CMB in all models. These down- 
wellings modulate the location of hot material such that it becomes concentrated into large-scale structures beneath Africa and the Pacific. The Pacific anomaly is approximately circular, while the African anomaly is a NWSE trending structure, extending southeastwards into the Indian Ocean. In TH models, these structures comprise clusters of plumes and interconnected hot (slow), linear ridges, whereas in TC models they represent discontinuous chemical 'piles'. These piles cover around $40 \%$ of the CMB, with the highest temperatures (lowest S-wave velocities) predicted at their edges. At $\sim 2480 \mathrm{~km}$ depth, $\mathrm{pPv}$ is present locally in high-velocity regions (pyrolite composition) in both $\mathrm{TH}$ and TC models, resulting in increased $V_{S}$ amplitudes. With depth, its occurrence becomes more wide-spread and the mineral physics tables predict that $\mathrm{pPv}$ is present everywhere at $\sim 2750 \mathrm{~km}$ depth, even for basaltic material (see Supplementary Fig. S1). We observe the strongest velocity variations around $2575 \mathrm{~km}$ depth, where large regions of bridgmanite material transform to post-perovskite. These large velocity variations are due to the removal of the radial average at each depth and expected for a phase transition (Styles et al., 2011). The presence of $\mathrm{pPv}$ affects $V_{P}$ variations in a similar way, except that it reduces their amplitudes rather than increasing them (Supplementary Fig. S2).

\subsection{Seismic resolution operator}

Following Ritsema et al. (2007), we define the resolution operator $\mathcal{R}=$ $\mathbf{G}^{\dagger} \mathbf{G}$, where $\mathbf{G}$ is the operator of the seismic forward problem and $\mathbf{G}^{\dagger}$ is its generalised inverse. We modify the geodynamic prediction of seismic heterogeneity (the "true" input model $\mathbf{m}^{\mathbf{I N}}$ ) by multiplying it with $\mathcal{R}$ to obtain a 
"filtered" output model $\mathbf{m}^{\text {OUT }}$ as if imaged by tomographic inversion:

$$
\mathbf{m}^{\mathrm{OUT}}=\mathcal{R} \cdot \mathbf{m}^{\mathrm{IN}}
$$

$\mathcal{R}$ fully describes the spatially heterogeneous resolution of the tomographic model. We have to compute $\mathcal{R}$ on the basis of the same damping parameter $\epsilon$ as the tomographic model. In SP12RTS, $\epsilon$ was 0.005 , corresponding to $\sim 1200$ unknowns, which we therefore adopt here as well.

In contrast to S40RTS, SP12RTS is a tomographic model of both $V_{S}$ and $V_{P}$ variations, hence the model vector $\mathbf{m}$ consists of two parts:

$$
\mathbf{m}=\left(\begin{array}{l}
\mathrm{S} \\
\mathbf{P}
\end{array}\right)
$$

where $\mathbf{S}$ and $\mathbf{P}$ are model vectors describing $\operatorname{dn} V_{S}$ and $\operatorname{dln} V_{P}$, respectively. We rewrite Equation 1 as follows:

$$
\left(\begin{array}{c}
\mathrm{S}^{\text {OUT }} \\
\mathrm{P}^{\text {OUT }}
\end{array}\right)=\left(\begin{array}{ll}
\mathcal{R}_{\mathrm{SS}} & \mathcal{R}_{\mathrm{SP}} \\
\mathcal{R}_{\mathrm{PS}} & \mathcal{R}_{\mathrm{PP}}
\end{array}\right)\left(\begin{array}{c}
\mathrm{S}^{\mathrm{IN}} \\
\mathrm{P}^{\mathrm{IN}}
\end{array}\right),
$$

where $\mathcal{R}_{\mathrm{SS}}$ and $\mathcal{R}_{\mathrm{PP}}$ are the diagonal blocks of $\mathcal{R}$ detailing how $V_{S}$ structure maps into $V_{S}$ structure (ditto for $V_{P}$ ). The off-diagonal blocks of $\mathcal{R}$, i.e. $\mathcal{R}_{\mathrm{SP}}$ and $\mathcal{R}_{\mathrm{PS}}$, contain information about how $V_{S}$ and $V_{P}$ structures map into each other (i.e. leakage of structure).

The resolution operator is dominantly diagonal (Koelemeijer et al., 2016), but $\mathcal{R}_{\mathrm{SP}}$ and $\mathcal{R}_{\mathrm{PS}}$ are not strictly zero. Therefore, some artefacts arise during tomographic filtering. Hence, it is crucial to use the full resolution operator incorporating the off-diagonal blocks when filtering geodynamic models. We note that the resolution of SP12RTS in the lower mantle is similar for $\operatorname{dn} \ln V_{S}$ and $\operatorname{dn} V_{P}$, which is important when considering their ratio. 
3. Effects of tomographic filtering on the S/P ratio and S-C correlation

To ensure meaningful comparisons - geodynamic models contain typically 80 million grid points, whereas SP12RTS was constructed with only 3500 parameters - we first have to reparameterise all original geodynamic models to the SP12RTS parameterisation (i.e. 21 splines with depth and spherical harmonics up to degree 12). Reparameterisation leads to a drastic reduction in the model dimensionality, broadening structures and reducing amplitudes of negative anomalies (low velocities) more ( $\sim 20-50 \%$ lower) than those of positive anomalies ( $\sim 0.5-15 \%$ lower) (Fig. 4a-b). Subsequently, we multiply the reparameterised models with $\mathcal{R}$, which effectively acts as a low-pass filter (Ritsema et al., 2007; Schuberth et al., 2009a), causing structures to broaden and weaken further (Fig. 4c). As the reparameterisation and filtering affect $V_{S}$ and $V_{P}$ structure differently in different locations, we explicitly consider here their effects on the S/P ratio and S-C correlation.

[Fig. 4 about here.]

\subsection{Global properties}

In this paper, we always compute the velocity ratios and correlations with respect to each model's radial average. In addition, we consistently compute them using the spherical harmonic coefficients where possible, which allows us to consider different spherical harmonic degrees directly. For the highresolution models, which are not parameterised in spherical harmonics, we use the RMS velocities, which results generally in the same curves (Koelemeijer et al., 2016). The resulting values are larger compared to using the 
median of the distribution (Koelemeijer et al., 2016). However, we prefer this approach as it means we do not divide by small values, which require special treatment (Tesoniero et al., 2016).

The presence of $\mathrm{pPv}$ is evident in the depth profiles of the original geodynamic models (Fig. 5a). At lowermost mantle depths where bridgmanite and $\mathrm{pPv}$ coexist (i.e. lateral variations in the presence of $\mathrm{pPv}$ occur), the $\mathrm{S} / \mathrm{P}$ ratio increases and we observe a pronounced, negative $\mathrm{S}-\mathrm{C}$ correlation. Both the $\mathrm{S} / \mathrm{P}$ ratio and the $\mathrm{S}-\mathrm{C}$ correlation curves peak around $2650 \mathrm{~km}$ depth, when most material has transformed to $\mathrm{pPv}$. We only observe a single peak in the $\mathrm{S} / \mathrm{P}$ ratio, rather than the typical peak-trough behaviour of a phase transition (Styles et al., 2011), as the RMS velocities are always positive.

Upon reparameterisation (Fig. 5b), minor artefacts are present in the model with $\mathrm{pPv}$, because the smooth spline interpolation cannot capture the sharp depth changes in the ratio and correlation. We find stronger artefacts after tomographic filtering (Fig. 5c), primarily due to the non-zero off-diagonal terms of $\mathcal{R}$. This especially affects the S-C correlation as we construct $\operatorname{d} \ln V_{C}$ using $\operatorname{d} \ln V_{S}$ and $\operatorname{d} \ln V_{P}$, both with their own limited resolution. For model $\mathrm{TH}-\mathrm{pPv}$, the filtering results in a negative $\mathrm{S}-\mathrm{C}$ correlation at depths as shallow as $\sim 1800 \mathrm{~km}$. In addition, the thermal model without pPv ( $\mathrm{TH}-\mathrm{nopPv}$ ), originally displaying a positive $\mathrm{S}-\mathrm{C}$ correlation, now displays a small, negative $\mathrm{S}-\mathrm{C}$ correlation that is entirely artificial. When we consider degree 2 structure only, artefacts are smaller and the S-C correlation of model TH-nopPv remains positive (Fig. 5c).

Despite the artefacts mentioned above, the effect of $\mathrm{pPv}$ remains evident throughout the processing steps, even when we account for the limited to- 
mographic resolution. We consistently observe a high $\mathrm{S} / \mathrm{P}$ ratio and negative $\mathrm{S}-\mathrm{C}$ correlation due to $\mathrm{pPv}$ in the $\mathrm{TH}$ models, as also noted by Della Mora et al. (2011). The same trends are observed for TC models (Supplementary Fig. S3), although the presence of additional basalt material in the lowermost mantle complicates the patterns. On the contrary, the correlation between $\mathrm{d} \ln V_{S}$ and $\mathrm{d} \ln V_{P}$ (S-P correlation) is high in all geodynamic models, even after filtering (Supplementary Fig. S4). Therefore, we cannot use this property to probe for the presence of $\mathrm{pPv}$ and/or chemical heterogeneity.

[Fig. 5 about here.]

\subsection{Fast and slow clusters}

For lowermost mantle structure, clusters of fast and slow velocities capture the differences between the LLVPs and the ambient mantle and thus provide more insights into the nature of seismic anomalies (Lekić et al., 2012). As the Clapeyron slope of the brg-pPv phase transition is positive (Cobden et al., 2014), we expect the transition to occur at shallower depth in cold regions (fast velocities in $\mathrm{TH}$ models) than in hot regions (slow velocities). Consequently, the $\mathrm{S} / \mathrm{P}$ ratio and $\mathrm{S}-\mathrm{C}$ correlation peak at different depths in regions of fast and slow velocities, giving rise to a depth offset between the two. Here, we consider whether such a depth offset remains distinct after reparameterisation and filtering.

We split every geodynamic model into two clusters using the fast $\left(\operatorname{d} \ln V_{S}>\right.$ $0)$ and slow $\left(\operatorname{dn} V_{S}<0\right)$ anomalies of the models themselves. We compute the geographic locations of both clusters at a reference depth of $2850 \mathrm{~km}$ and subsequently use this for all depths in the mantle, similar to Lekić et al. (2012). 
We exclude all points for which $\operatorname{d} \ln V_{S}$ or $\operatorname{d} \ln V_{P}$ are smaller than $0.01 \%$. This approach is different from Koelemeijer et al. (2016) who split SP12RTS into fast and slow clusters using the vote map of Lekić et al. (2012). However, the vote map is based on the geographic distribution of seismic anomalies. Using the same approach for geodynamic models would not be meaningful, as the distribution of seismic structure depends on plate reconstructions and unknown initial conditions.

Using the cluster definition described above, original geodynamic models indeed feature a depth offset of $\sim 100 \mathrm{~km}$ between the fast and slow cluster, especially in the S-C correlation (Fig. 6). After reparameterisation (Fig. 6b), the offset decreases $(\leq 50 \mathrm{~km})$ due to the broad spline spacing of SP12RTS in the lowermost mantle. Tomographic filtering removes this remaining depth offset, and we observe almost no difference in the filtered clusters (Fig. 6c). This implies that even if there is a depth offset between fast and slow velocity regions, it is not resolved by SP12RTS. It is thus not surprising that no depth offset was observed in SP12RTS itself (Koelemeijer et al., 2016). By incorporating a finer depth parameterisation, future studies may be able to improve on this.

[Fig. 6 about here.]

\section{Results}

\subsection{Tomographic-geodynamic model comparisons}

The amplitudes of SP12RTS (Fig. 2, third column) are most compatible with those observed in filtered TH models (Fig. 4c), whereas the amplitudes in filtered TC models are too large (Davies et al., 2012), particularly 
for $\operatorname{d} \ln V_{P}$. Nevertheless, all geodynamic models reproduce the large-scale patterns of SP12RTS at this depth, with low velocity anomalies at the locations of the LLVPs, surrounded by higher-than-average velocities. We focus from hereon only on the $\mathrm{S} / \mathrm{P}$ ratio and $\mathrm{S}-\mathrm{C}$ correlation within a given model (computed directly from the spherical harmonic coefficients), removing the dependence on the plate reconstructions employed in the geodynamic simulations. We do not calculate tomographic-geodynamic model correlations, as these quantities would primarily inform us about the uncertainties in the plate reconstructions, rather than help us to constrain the origin of seismic anomalies.

Models with pPv match SP12RTS well below depths of $\sim 2300 \mathrm{~km}$ (Fig. 7) as they display an increased $\mathrm{S} / \mathrm{P}$ ratio and a more negative $\mathrm{S}-\mathrm{C}$ correlation in the lower mantle. However, the $\mathrm{S} / \mathrm{P}$ ratio peaks $\sim 100 \mathrm{~km}$ deeper than in SP12RTS. Although models without pPv also feature a (small) negative S-C correlation (an artefact of the tomographic filtering as shown in the previous section), they fail to produce a high $\mathrm{S} / \mathrm{P}$ ratio. The difference between models with and without $\mathrm{pPv}$ is particularly strong for degree-2 structure (Fig. 7b), where models with $\mathrm{pPv}$ are in close agreement with SP12RTS in the lowermost mantle (below $\sim 2300 \mathrm{~km}$ depth). Between $1700 \mathrm{~km}$ and $2300 \mathrm{~km}$, all geodynamic models fail to reproduce the negative S-C correlation observed in SP12RTS. The addition of a chemically distinct phase (model TC-pPv) changes the amplitude of the $\mathrm{S} / \mathrm{P}$ ratio, but it does not significantly improve the overall match with SP12RTS. Therefore, we conclude that both TH and TC models reproduce the main statistical properties of SP12RTS equally well, if $\mathrm{pPv}$ is present. 
Although there is no difference between fast and slow clusters after tomographic filtering (Fig. 6), TH-pPv and TC-pPv (i.e. geodynamic models with $\mathrm{pPv}$ ) reproduce the high $\mathrm{S} / \mathrm{P}$ ratio and negative $\mathrm{S}-\mathrm{C}$ correlation in both clusters and thus match the large-scale characteristics of SP12RTS (Fig. 8). Hence, pPv could also be used as an explanation for observations of a high $\mathrm{S} / \mathrm{P}$ ratio and negative $\mathrm{S}-\mathrm{C}$ correlation inside LLVPs, even though we expect these to be hotter than the surrounding mantle. However, one should keep in mind that the seismically slow regions (i.e. LLVPs) in filtered models also incorporate cold regions (i.e. with $\mathrm{pPv}$ ) in the high-resolution models. Note also that $\mathrm{pPv}$ is not necessarily present at the same depths in both clusters (this depth sensitivity is lost during tomographic filtering). In addition, we have not imposed its presence in the LLVPs - this is a consequence of physically constrained dynamic models combined with mineral physics predictions for a reasonable mantle composition. Thus, our results merely imply that it is plausible for post-perovskite to be present within the seismically-imaged LLVPs and that its presence there explains tomographic features.

[Fig. 8 about here.]

\subsection{Effects of inversion data weighting}

SP12RTS contains data from body waves, surface waves and normal modes, with weighting factors imposed between the different data sets. For the default SP12RTS model, the data weights were chosen to balance the sensitivities of body-wave and normal-mode data (Koelemeijer et al., 2016). 
To investigate the robustness of our results, we repeat our tomographicgeodynamic model comparison for inversions dominated either by normalmode splitting functions or body-wave traveltimes. This means that we multiply our reparameterised models by $\mathcal{R}_{s}$ (normal-modes dominated) and $\mathcal{R}_{t}$ (body-waves dominated) and compare these with the corresponding versions of SP12RTS (i.e. SP12RTS $s$ and SP12RTS $t$, respectively).

Models filtered using $\mathcal{R}_{s}$ (normal-modes dominated) show a clear difference due to the presence of $\mathrm{pPv}$ (Fig. 9a), with the best match again when $\mathrm{pPv}$ is present (Fig. 9). For models filtered with $\mathcal{R}_{t}$ (body-waves dominated), we observe that the high $\mathrm{S} / \mathrm{P}$ ratio and negative $\mathrm{S}-\mathrm{C}$ correlation are artificially smeared upwards to depths of $\sim 2000 \mathrm{~km}$. A likely reason for this is that our filtering does not capture the uncertainties in the underlying theory of the tomographic inversion, in this case ray theory. Neglecting finite-frequency effects in combination with vertical ray paths thus leads to artificial high $\mathrm{S} / \mathrm{P}$ ratios and a negative $\mathrm{S}-\mathrm{C}$ correlation in the body-wave dominated inversions (Malcolm and Trampert, 2011). Thus, we argue that studies of the $\mathrm{S} / \mathrm{P}$ ratio based on body-wave ray theory (e.g. Su and Dziewonski, 1997; Della Mora et al., 2011) cannot be used to distinguish between thermal and chemical variations, consistent with recent work by Tesoniero et al. (2016).

[Fig. 9 about here.]

A spectral decomposition of model TH-pPv filtered using $\mathcal{R}_{s}, \mathcal{R}$ and $\mathcal{R}_{t}$ further illustrates the importance of the data weighting on the robust retrieval of the $\mathrm{S} / \mathrm{P}$ ratio and $\mathrm{S}-\mathrm{C}$ correlation (Supplementary Fig. S5). We recover the features of the reparameterised model (a high $\mathrm{S} / \mathrm{P}$ ratio and negative $\mathrm{S}$ C correlation at all spherical harmonic degrees) well using $\mathcal{R}_{s}$ (normal-mode 
dominated) for even spherical harmonic degrees. For SP12RTS (filtering using $\mathcal{R}$ ), we recover even degrees up to $l=10$. However, the odd degrees display more artefacts, as the self-coupled splitting function data only constrain even-degree structure. When using $\mathcal{R}_{t}$ (body-waves dominated), we observe an increase in the $\mathrm{S} / \mathrm{P}$ ratio at lowermost mantle depths and an artificial upward smearing of the negative S-C correlation to depths of $1800 \mathrm{~km}$ for all spherical harmonic degrees. This demonstrates that the depth extent of the negative S-C correlation depends on the weighting of the data sets, with more severe smearing occurring when we give more weight to bodywave data (if treated with ray theory). This is a possible explanation for the differences between previous tomographic models: the body-wave model of Su and Dziewonski (1997) featured a negative S-C correlation throughout the mantle, whereas the long-period model of Masters et al. (2000) only contained a negative correlation in the lowermost mantle (Fig. 1). We speculate that these studies imaged the same structures, filtered and smeared differently due to the differences in theoretical approximations in their respective inversion schemes.

\subsection{Influence of the Clapeyron slope}

The mineral physics table for pyrolite used here predicts that $\mathrm{pPv}$ is present everywhere at the CMB due to the shallowing of the Clapeyron slope at high temperature (see Supplementary Fig. S1). To test the influence of the Clapeyron slope on the $\mathrm{S} / \mathrm{P}$ ratio and $\mathrm{S}-\mathrm{C}$ correlation, as well as their fit to SP12RTS, we use two additional mineral physics tables as described in the Supplementary Material and shown in Fig. 10a). In these tables, "TH-pPv-extra" and "TH-pPv-extra100", we assume a constant Clapeyron 
slope of $\sim 13 \mathrm{MPa} / \mathrm{K}$ (i.e. the one found at low temperatures) and linearly extrapolate (i.e. non-physical) the phase boundary down to the CMB. This way, we enforce a pPv-free $\mathrm{CMB}$ while at shallower depth either $\mathrm{pPv}$ is everywhere except in the lowest velocity regions ( $\mathrm{TH}-\mathrm{pP}$-extra) or $\mathrm{pPv}$ only occurs as lenses in the highest velocity regions (TH-pPv-extra100) (Fig. 10b).

For the $\mathrm{TH}$-pPv-extra model, we observe increased $\mathrm{S} / \mathrm{P}$ ratios down to the CMB (Fig. 10c), whereas the TH-pPv-extra100 model results in lower $\mathrm{S} / \mathrm{P}$ ratios. For both these models, the peak in the $\mathrm{S} / \mathrm{P}$ ratio also occurs at greater depth as the stability field is shifted downwards. The different mineral physics tables produce a larger variation in the $\mathrm{S} / \mathrm{P}$ ratio and $\mathrm{S}-\mathrm{C}$ correlation compared to Fig. 7b. As the mineral physics tables are characterised by a different areal extent of $\mathrm{pPv}$ (Fig. 10b), we suggest that this areal extent has a strong control on the $\mathrm{S} / \mathrm{P}$ ratio and $\mathrm{S}-\mathrm{C}$ correlation, an idea we explore further in Section 5.1. We also note that even the effect of small lenses of $\mathrm{pPv}$ (the TH-pPv-extra100 model) is observable in the synthetic tomography images.

The shape of the $\mathrm{S}-\mathrm{C}$ correlation curve for degree 2 is reproduced best by the original TH-pPv model, as the $\mathrm{S}-\mathrm{C}$ correlation remains negative for the extrapolated tables (Fig. 10d). This is confirmed by calculating the L2norm between the $\mathrm{S} / \mathrm{P}$ ratio and $\mathrm{S}-\mathrm{C}$ correlation curves of SP12RTS and the geodynamic models (Fig. 10e-f). Lower misfits are generally found when $\mathrm{pPv}$ has a larger areal extent (higher "pPv coverage") as in the original TH-pPv model, particularly for the L2-norm based on the S-C correlation. On the other hand, models with $\mathrm{pPv}$ lenses and a $\mathrm{pPv}$-free $\mathrm{CMB}$ region (the $\mathrm{TH}$ pPv-extra and TH-pPv-extra100 models) do not reproduce the decrease in 
the $\mathrm{S} / \mathrm{P}$ ratio in SP12RTS and the increase in the $\mathrm{S}-\mathrm{C}$ correlation close to the $\mathrm{CMB}$, resulting in a higher misfit. A spectral decomposition of the different models also suggests that the original TH-pPv model provides the closest fit to the seismic characteristics of SP12RTS at other spherical harmonic degrees (Supplementary Fig. S6). These results imply that the statistical properties of SP12RTS, particularly the positive values of the S-C correlation close to the $\mathrm{CMB}$, are matched best by a pPv-bearing $\mathrm{CMB}$ region, an idea that is consistent with work by Cobden et al. (2012) using core diffracted phases.

[Fig. 10 about here.]

\section{Discussion}

We observe only small differences between isochemical and thermochemical models, whereas the areal extent of pPv makes a large difference (Fig. 10). Here, we will first discuss the dominant controls on the $\mathrm{S} / \mathrm{P}$ ratio and $\mathrm{S}-\mathrm{C}$ correlation. Then, we discuss the influence of the uncertainties in the mineralogical model on our results. Subsequently, we indicate which seismological features our geodynamic models cannot explain, before ending by considering the implications of our results on the the presence of $\mathrm{pPv}$ and the nature of lower mantle heterogeneity.

\subsection{Dominant controls on the $S / P$ ratio and $S-C$ correlation}

The large similarity in $\mathrm{S} / \mathrm{P}$ ratio and $\mathrm{S}-\mathrm{C}$ correlation for $\mathrm{TH}$ and $\mathrm{TC}$ models (despite the presence of large-scale chemical heterogeneity resulting in a different planform of convection) is partly due to the fact that the 
reparameterisation and tomographic filtering act as low-pass filters (see Section 3). However, the S-C correlation is already markedly negative in highresolution models with $\mathrm{pPv}(\mathrm{TH}-\mathrm{pPv}$ in Fig. 5a and $\mathrm{TC}-\mathrm{pPv}$ in Supplementary Fig. S3a). The reason for this is that a similar amount of $\mathrm{pPv}$ is present at any given depth in both TH and TC scenarios (Fig. 3). Although the hotter areas have a larger extent in the TC-pPv model, they contain basaltic material, which transforms to $\mathrm{pPv}$ at shallower depths due to the negative Clapeyron slope for basalt at high temperatures (Supplementary Fig. S1b). In addition, the geotherms and temperature distributions of both $\mathrm{TH}$ and TC models are similar with the majority of temperatures close to the average (Supplementary Fig. S1). The large similarity in the distribution of $\mathrm{pPv}$ results in almost indistinguishable values of the $\mathrm{S} / \mathrm{P}$ ratio and $\mathrm{S}-\mathrm{C}$ correlation, with only a small effect from the assumed mantle composition. Tesoniero et al. (2016) came to a similar conclusion, although they considered different compositions for one-dimensional profiles rather than lateral compositional variations.

The assumed CMB temperature has also only a minor effect on the $\mathrm{S} / \mathrm{P}$ ratio and S-C correlation (Supplementary Fig. S7). Again, the geotherms and temperature distributions throughout the mantle are similar (Supplementary Material and Supplementary Fig. S8). The CMB temperature only affects the excess plume temperatures, not the temperature of subducting material, and slow clusters (hot areas) thus show (slightly) larger differences. However, after filtering, only the slow cluster with $T_{C M B}=4400 \mathrm{~K}$ is distinguishable (Supplementary Fig. S7c). Consequently, we cannot place constraints on the CMB temperature using our tomographic-geodynamic model comparisons. 
Throughout our results, we observe that the areal extent of $\mathrm{pPv}$ introduces the largest variations in the $\mathrm{S} / \mathrm{P}$ ratio and $\mathrm{S}-\mathrm{C}$ correlation curves (see Fig. 10 and Supplementary Fig. S6). Supplementary Fig. S9 illustrates this further, by plotting the percentage coverage of $\mathrm{pPv}$ at any depth versus the $\mathrm{S} / \mathrm{P}$ ratio and $\mathrm{S}-\mathrm{C}$ correlation in the high-resolution models. $\mathrm{S} / \mathrm{P}$ ratios larger than $\sim 3$ and strongly negative values of the $\mathrm{S}-\mathrm{C}$ correlation are observed only for a $\mathrm{pPv}$ coverage of 10-90\%. These findings thus imply that in fact it is a partial coverage of $\mathrm{pPv}$ (i.e. lateral variations in $\mathrm{pPv}$ presence) that produce larger ratios and a negative $\mathrm{S}-\mathrm{C}$ correlation, rather than $\mathrm{pPv}$ being present everywhere or nowhere. This is consistent with the notion that lateral variations in a phase transition have a large effect on averaged quantities (Styles et al., 2011).

Fig. 10f indicates a clear trend between the L2 norm based on the S-C correlation and the percentage coverage of $\mathrm{pPv}$ at $2700 \mathrm{~km}$ depth. Thermochemical (TC) models and models with different CMB temperatures follow the same trend, indicating again that the lateral areal extent of $\mathrm{pPv}$ has the strongest effect on the $\mathrm{S} / \mathrm{P}$ ratio and $\mathrm{S}-\mathrm{C}$ correlation. Therefore, these seismic characteristics can only be used to determine the areal extent of $\mathrm{pPv}$ and not the composition of the lowermost mantle or CMB temperature.

\subsection{Mineral physics uncertainties}

We assume a pyrolitic mantle composition, which is a reasonable choice according to recent studies (Davies et al., 2012; Zhang et al., 2013; Shim et al., 2017), and an additional basaltic component in the TC case. Although ironrich compositions have been suggested as representative for LLVPs, a basaltic composition was favoured by Davies et al. (2012) based on its high density 
and ability to produce a negative S-C correlation. Given the dominance of $\mathrm{pPv}$ on the $\mathrm{S} / \mathrm{P}$ ratio and $\mathrm{S}-\mathrm{C}$ correlation, we believe that the main effect of a different mantle composition is to shift the stability field of $\mathrm{pPv}$ in depth and thus to change the lateral distribution of pPv. For example, it would occur shallower for MORB or iron-rich material and deeper for harzburgite or Alrich material (Cobden et al., 2014). The uncertainty in mantle composition is thus addressed by our tests with the extrapolated mineral physics tables, even though these are un-physical.

To convert the temperature and composition fields to seismic velocities, we have opted to use a thermodynamic mineralogical model (Stixrude and Lithgow-Bertelloni, 2011) in which the Clapeyron slope of the brg-pPv transition is non-linear for both pyrolite and basalt. This is in contrast to the general notion of a constant Clapeyron slope assumed in past studies, but the thermodynamic approach is preferable given its self-consistency and the fact that no experimental measurements exist for temperatures above $\sim 3000 \mathrm{~K}$. In fact, there is no reason to expect a linear Clapeyron slope for the phase transition and our results for the extrapolated tables show that a linear Clapeyron slope does not improve the fit to the seismic data. Furthermore, the values of 3-13 MPa/K in the mineralogical model are consistent with Clapeyron slope estimates from experiments and theoretical calculations (e.g. Hirose, 2006; Stixrude and Lithgow-Bertelloni, 2011; Cobden et al., 2014).

The mineralogical tables are reproducible using an alternative software implementation of the Gibbs free energy minimisation algorithm and equation of state calculations for the same database (Chust et al., 2017). Thus, the database parameters are the primary control on the phase transition 
depth and the values of the Clapeyron slopes. We may need to re-evaluate the robustness of our findings after additional experimental data at high temperature become available, or for other choices of parameters in the mineralogical tables (e.g. the crystal structure of Ca-Pv (Stixrude et al., 2007)). However, until then, our results show that for widely-used parameters, a pPvbearing $\mathrm{CMB}$ region explains several lower mantle characteristics of global tomography models. This is consistent with work by Mosca et al. (2012) and Cobden et al. (2012), who, based on a large range of mineralogical models, also favoured models with pPv to explain lower mantle seismological observations.

\subsection{Mid-mantle discrepancy}

A discrepancy remains between SP12RTS and the geodynamic models between $1800 \mathrm{~km}$ and $2300 \mathrm{~km}$ depth, where SP12RTS features an increased $\mathrm{S} / \mathrm{P}$ ratio and the onset of a negative $\mathrm{S}-\mathrm{C}$ correlation (Fig. 7). Given that we account for the limited tomographic resolution, we cannot explain this discrepancy with $\mathrm{pPv}$, or more accurately, not with the parameters constraining the stability field of $\mathrm{pPv}$ in the different mineral physics tables. As mentioned before, the stability field of $\mathrm{pPv}$ is not well constrained in high-pressure, high-temperature experiments, even for pure $\mathrm{MgSiO}_{3}$ (Cobden et al., 2014). Differences of 5-10 GPa in the transition pressure exist due to the pressure standard used in experiments (Tsuchiya et al., 2004; Hirose, 2006) and additional errors of 5-10 GPa could be introduced due to reversing the phase boundary. Therefore, it is possible that $\mathrm{pPv}$ is present at (slightly) shallower depths than currently assumed. However, given the small changes in peak depth for different Clapeyron slopes (Fig. 10), we question 
whether it would explain the discrepancy entirely.

The iron spin transition provides another explanation for the discrepancy at $1800-2300 \mathrm{~km}$ depth, as this gradually affects seismic properties without producing sharp discontinuities (e.g. Stackhouse et al., 2007; Wentzcovitch et al., 2009). The effect of the spin transition in bridgmanite remains debated, but for ferropericlase, the spin transition has a clear effect on the seismic velocities. It primarily changes the bulk modulus (e.g. Wentzcovitch et al., 2009; Marquardt et al., 2009), which results in a drop of $V_{P}$ with no change in $V_{S}$; hence the $\mathrm{S} / \mathrm{P}$ ratio increases and the $\mathrm{S}-\mathrm{C}$ correlation becomes negative. The depth range where this effect is expected depends on temperature, occurring typically deeper and over a wider depth range with increasing temperature, e.g. around $75 \mathrm{GPa}(1700 \mathrm{~km}$ depth) for a temperature of $2500 \mathrm{~K}$ (Marquardt et al., 2009). This effect of the spin transition, unaccounted for in the mineralogical model employed here, could help to resolve the discrepancy at mid-mantle depths. Whether incorporating changes in the oxidation state of iron, as suggested recently by Shim et al. (2017), or shear softening of Ca-Pv (Stixrude et al., 2007) improves the fit between SP12RTS and the geodynamic models further, remains to be seen. Finally, we cannot exclude the possibility that a negative $\mathrm{S}-\mathrm{C}$ correlation at these depths $(1800-2300 \mathrm{~km})$ is due to the presence of chemical heterogeneity, i.e. tall, chemically distinct LLVPs. Although it would be difficult to predict their exact composition, the presence of MORB or iron-rich material (due to the accumulation of subducted crust or core-reaction products) would cause the $\mathrm{pPv}$ transition to occur at shallower depth, thereby reducing the mid-mantle discrepancy. 


\subsection{Implications for lower mantle structures}

We show that the features of SP12RTS are best reproduced by the original mineral physics table, and thus by a pPv-bearing CMB region (Fig. 10e-f). We propose two different scenarios to achieve this, based on our tomographicgeodynamic comparisons. One possibility is that the Clapeyron slope of the brg-pPv transition in pyrolite shallows at high temperature, as predicted by the original mineral physics table (Supplementary Fig. S1a). Alternatively, the Clapeyron slope has a higher, constant slope, but the entire stability field of $\mathrm{pPv}$ is shifted to shallower depths than has been considered here. A shallower stability field of $\mathrm{pPv}$ would likely give rise to a shallower peak depth of the $\mathrm{S} / \mathrm{P}$ ratio. This may thus improve the mismatch in peak depth currently observed between SP12RTS and the geodynamic models with $\mathrm{pPv}$ (Fig. 7), given that no improvement is observed for a change in the CMB temperature. To distinguish between the two proposed scenarios, mineral physics measurements of bridgmanite/pPv at high temperature $(>3000 \mathrm{~K})$ and pressures above $115 \mathrm{GPa}$ are required.

For a $\mathrm{pPv}$-bearing $\mathrm{CMB}$ region, $\mathrm{pPv}$ needs to be stable at temperatures as high as 3600-4000 K. Whether such temperatures are too high remains debated, as solidus temperatures vary between $\sim 4150 \mathrm{~K}$ (Andrault et al., 2011) and 3570 $\pm 200 \mathrm{~K}$ (Nomura et al., 2014). Nevertheless, our results for different CMB temperatures indicate that even for a CMB temperature of $3600 \mathrm{~K}$, the characteristics of SP12RTS are reproduced best by models with pPv everywhere, including inside the LLVPs (Supplementary Fig. S7). The occurrence of $\mathrm{pPv}$ within the LLVPs remains debated (Garnero et al., 2016), complicated by uncertainties in estimates of its stability field and 
its dependence on chemical composition (Cobden et al., 2014). However, recent normal-mode studies (Koelemeijer et al., 2017) and body-wave studies (Cobden et al., 2012) have favoured the presence of $\mathrm{pPv}$ within the LLVPs. When considering the presence of $\mathrm{pPv}$ inside tomographically-imaged LLVPs, it is also important to keep in mind that they may contain smaller-scale features (i.e. cold regions containing $\mathrm{pPv}$ ), which are lost due to the limited resolution in tomography.

For the two possible scenarios described above, it is unlikely that the geotherm crosses the phase boundary a second time just above the CMB for CMB temperatures of 3600-4400 K. Hence, seismic observations of paired discontinuities can no longer be explained by a double crossing of the phase transition, as assumed by previous authors in efforts to constrain the CMB heat flux (e.g. Hernlund et al., 2005; Lay et al., 2008). Instead, the stishoviteseifertite transition in the silicate system could potentially explain these observations (Grocholski et al., 2013). In addition, the temperature-pressure dependence of the Clapeyron slope may reconcile differences observed in the depth of the D" discontinuity without the need to invoke local chemical heterogeneity.

\section{Conclusions}

By comparing the statistical properties of tomographic model SP12RTS with synthetic tomography models derived from geodynamic simulations with and without post-perovskite and/or chemical heterogeneity, we have shown that:

1. We can identify the signature of $\mathrm{pPv}$ in global tomography models, 
even when accounting for the limited resolution of seismic tomography.

2. Lateral variations in the presence of $\mathrm{pPv}$ give rise to a negative $\mathrm{S}-\mathrm{C}$ correlation and high $\mathrm{S} / \mathrm{P}$ ratio below $2300 \mathrm{~km}$ depth, explaining seismic characteristics.

3. Due to the dominant control of $\mathrm{pPv}$, one cannot constrain the composition of the lowermost mantle using seismic observations of the $\mathrm{S} / \mathrm{P}$ ratio and $\mathrm{S}-\mathrm{C}$ correlation.

4. The characteristics of SP12RTS are reproduced best for a CMB region covered by $\mathrm{pPv}$, implying the presence of $\mathrm{pPv}$ inside the LLVPs.

5. Two scenarios are proposed for the brg-pPv transition: a shallowing of the Clapeyron slope at high temperature or a shallower stability field for $\mathrm{pPv}$.

6. Our comparisons cannot be used to constrain the CMB temperature due to our limited tomographic resolution.

7. Observed differences in the predicted depth of the negative S-C correlation, across a number of studies, are likely related to the data types used in the inversion procedures, with body-wave models artificially smearing the signal upwards to shallower depths.

8. A discrepancy between SP12RTS and geodynamic predictions remains at mid-mantle depths (1800-2300 km), which could be due to uncertainties in the mineralogical model, unaccounted effects of the spin transition and/or the presence of shallower chemical heterogeneity.

Throughout our comparisons, we have stressed the importance of tomographic filtering. This aids not only the identification of robust features in tomographic models, but it is also essential for meaningful comparisons 
between tomographic and geodynamic models. The tomographic filter of SP12RTS, which filters both $V_{S}$ and $V_{P}$ structures jointly without any apriori constraints, has an improved resolution close to the CMB compared to other studies and has been developed specifically to enable comparisons of seismic velocity ratios and correlations. Consequently, interested parties are encouraged to incorporate the SP12RTS filtering software (available online).

Despite the uncertainties in mantle composition and assumptions in the geodynamic modelling, we have demonstrated that a pPv-bearing CMB region is preferred for explaining the decrease in the $\mathrm{S} / \mathrm{P}$ ratio towards the $\mathrm{CMB}$. The inference that $\mathrm{pPv}$ is present everywhere close to the $\mathrm{CMB}$, also inside the LLVPs, should not be ignored as a possibility in future studies. In addition, our study indicates the potential for constraining the Clapeyron slope of the brg-pPv phase transition using global tomography, especially if future studies incorporate a denser depth parameterisation in the lowermost mantle.

\section{Acknowledgements}

We thank the Editor (Peter Shearer), Lapo Boschi and an anonymous reviewer for their comments, which significantly improved the manuscript. PK is funded by a Junior Research Fellowship from University College, Oxford and acknowledges support from an ETH Zürich Postdoctoral Fellowship (ETH/COFUND FEL-25 13-2, grant agreement number 0-20997-14). DRD is funded by an ARC Future Fellowship (FT140101262) and JR is supported by NSF grant EAR-1416695. AD was also funded by the ERC under the European Union's Horizon 2020 research and innovation programme (grant 
agreement no. 681353 ATUNE) and a Vici award number 016.160.310/526 from the Netherlands organisation for scientific research (NWO). Further funding was provided by Pembroke College, Cambridge and the European Research Council (ERC) under the European Community's Seventh Framework Programme (FP7/2007-2013)/ERC grant agreement number 204995. We thank Carolina Lithgow-Bertelloni, Lars Stixrude and Thomas Chust for providing mineralogical tables as well as feedback on mineral physics aspects. We also thank Ana Ferreira and Keith Priestley for helpful comments. PK is grateful to University College London for hosting her as an academic visitor, which facilitated discussions. Mantle dynamics simulations were undertaken on the NCI National Facility in Canberra, Australia, which is supported by the Australian Commonwealth Government. Figures have been produced using the Generic Mapping Tools (GMT) version 5 software (Wessel et al., 2013).

Andrault, D., Bolfan-Casanova, N., Nigro, G. L., Bouhifd, M. A., Garbarino, G., Mezouar, M., 2011. Solidus and liquidus profiles of chondritic mantle: Implication for melting of the Earth across its history. Earth Planet. Sci. Lett.304 (1-2), 251-259.

Baumgardner, J. R., 1985. Three-dimensional treatment of convective flow in the Earth's mantle. J. Stat. Phys.39 (5), 501-511.

Chust, T. C., Steinle-Neumann, G., Dolejs, D., Schuberth, B. S., Bunge, H. P., 2017. MMA-EoS: A computational framework for mineralogical thermodynamics. J. Geophys. Res.122, 9881-9920.

Cobden, L., Mosca, I., Trampert, J., Ritsema, J., 2012. On the likelihood of 
post-perovskite near the core-mantle boundary: A statistical interpretation of seismic observations. Phys. Earth Planet. Inter.210, 21-35.

Cobden, L., Thomas, C., Trampert, J., 2014. Seismic detection of postperovskite inside the Earth. The Earth's heterogeneous mantle.

Davies, D. R., Davies, J. H., Bollada, P. C., Hassan, O., Morgan, K., Nithiarasu, P., 2013. A hierarchical mesh refinement technique for global 3D spherical mantle convection modelling. Geosci. Mod. Dev. 6, 1095-1107.

Davies, D. R., Goes, S., Davies, J. H., Schuberth, B. S. A., Bunge, H., Ritsema, J., 2012. Reconciling dynamic and seismic models of Earth's lower mantle: The dominant role of thermal heterogeneity. Earth Planet. Sci. Lett.353, 253-269.

Davies, D. R., Goes, S., Lau, H. C. P., 2015. Thermally Dominated Deep Mantle LLSVPs: A Review. In: Khan, A., Deschamps, F. (Eds.), The Earth's Heterogeneous Mantle. Springer International Publishing, pp. 441477.

Della Mora, S., Boschi, L., Tackley, P., Nakagawa, T., Giardini, D., 2011. Low seismic resolution cannot explain $\mathrm{S} / \mathrm{P}$ decorrelation in the lower mantle. Geophys. Res. Lett.38 (12).

Garnero, E., McNamara, A., Shim, S.-H., 2016. Continent-sized anomalous zones with low seismic velocity at the base of Earth's mantle. Nature Geosci.9 (7), 481-489. 
Grocholski, B., Shim, S.-H., Prakapenka, V., 2013. Stability, metastability, and elastic properties of a dense silica polymorph, seifertite. J. Geophys. Res.118 (9), 4745-4757.

Hernlund, J., Thomas, C., Tackley, P., 2005. A doubling of the postperovskite phase boundary and structure of the Earth's lowermost mantle. Nature434 (7035), 882-886.

Hirose, K., 2006. Postperovskite phase transition and its geophysical implications. Rev. Geophys.44.

Ishii, M., Tromp, J., 1999. Normal-mode and free-air gravity constraints on lateral variations in velocity and density of Earth's mantle. Science285 (5431), 1231.

Karato, S.-i., Karki, B. B., 2001. Origin of lateral variation of seismic wave velocities and density in the deep mantle. J. Geophys. Res.106 (R10), 2177121783.

Koelemeijer, P., Deuss, A., Ritsema, J., 2013. Observations of core-mantle boundary Stoneley modes. Geophys. Res. Lett.40 (11), 2557-2561.

Koelemeijer, P., Deuss, A., Ritsema, J., 2017. Density structure of Earth's lowermost mantle from Stoneley mode splitting observations. Nature Comm.8, 15241.

Koelemeijer, P., Ritsema, J., Deuss, A., Van Heijst, H.-J., 2016. SP12RTS: a degree-12 model of shear-and compressional-wave velocity for Earth's mantle. Geophys. J. Int.204 (2), 1024-1039. 
Lau, H. C., Mitrovica, J. X., Davis, J. L., Tromp, J., Yang, H.-Y., Al-Attar, D., 2017. Tidal tomography constrains Earth's deep-mantle buoyancy. Nature551 (7680), 321 .

Lay, T., Hernlund, J., Buffett, B., 2008. Core-mantle boundary heat flow. Nature Geosci.1 (1), 25-32.

Lekić, V., Cottaar, S., Dziewonski, A., Romanowicz, B., 2012. Cluster analysis of global lower mantle tomography: A new class of structure and implications for chemical heterogeneity. Earth Planet. Sci. Lett.357, 6877.

Malcolm, A. E., Trampert, J., 2011. Tomographic errors from wave front healing: more than just a fast bias. Geophys. J. Int.185 (1), 385-402.

Marquardt, H., Speziale, S., Reichmann, H. J., Frost, D. J., Schilling, F. R., 2009. Single-crystal elasticity of (Mg 0.9 Fe 0.1) O to 81 GPa. Earth Planet. Sci. Lett.287 (3), 345-352.

Masters, G., Laske, G., Bolton, H., Dziewonski, A., 2000. The relative behavior of shear velocity, bulk sound speed, and compressional velocity in the mantle: Implications for chemical and thermal structure. Geophys. Monograph AGU117, 63-87.

Mosca, I., Cobden, L., Deuss, A., Ritsema, J., Trampert, J., 2012. Seismic and mineralogical structures of the lower mantle from probabilistic tomography. J. Geophys. Res.117 (B6), B06304. 
Moulik, P., Ekström, G., 2016. The relationships between large-scale variations in shear velocity, density, and compressional velocity in the Earth's mantle. J. Geophys. Res.121 (4), 2737-2771.

Murakami, M., Hirose, K., Kawamura, K., Sata, N., Ohishi, Y., 2004. Postperovskite phase transition in MgSiO3. Science304 (5672), 855.

Nomura, R., Hirose, K., Uesugi, K., Ohishi, Y., Tsuchiyama, A., Miyake, A., Ueno, Y., 2014. Low core-mantle boundary temperature inferred from the solidus of pyrolite. Science, 1248186.

Oganov, A., Ono, S., 2004. Theoretical and experimental evidence for a postperovskite phase of MgSiO3 in Earth's D" layer. Nature430 (6998), 445448.

Ritsema, J., Deuss, A., van Heijst, H.-J., Woodhouse, J. H., 2011. S40RTS: a degree-40 shear-velocity model for the mantle from new Rayleigh wave dispersion, teleseismic traveltime and normal-mode splitting function measurements. Geophys. J. Int.184 (3), 1223-1236.

Ritsema, J., McNamara, A. K., Bull, A. L., 2007. Tomographic filtering of geodynamic models: Implications for model interpretation and large-scale mantle structure. J. Geophys. Res.112 (B1).

Romanowicz, B., 2001. Can we resolve 3D density heterogeneity in the lower mantle? Geophys. Res. Lett.28 (6), 1107-1110.

Schuberth, B., Bunge, H.-P., Ritsema, J., 2009a. Tomographic filtering of high-resolution mantle circulation models: Can seismic heterogeneity be explained by temperature alone? Geophys. Geochem. Geosys.10 (5). 
Schuberth, B., Bunge, H.-P., Steinle-Neumann, G., Moder, C., Oeser, J., 2009b. Thermal versus elastic heterogeneity in high-resolution mantle circulation models with pyrolite composition: High plume excess temperatures in the lowermost mantle. Geophys. Geochem. Geosys.10 (1).

Seton, M., Müller, R., Zahirovic, S., Gaina, C., Torsvik, T., Shephard, G., Talsma, A., Gurnis, M., Turner, M., Maus, S., et al., 2012. Global continental and ocean basin reconstructions since 200ma. Earth Sci. Rev.113 (3), $212-270$

Shim, S.-H., Grocholski, B., Ye, Y., Alp, E. E., Xu, S., Morgan, D., Meng, Y., Prakapenka, V. B., 2017. Stability of ferrous-iron-rich bridgmanite under reducing midmantle conditions. Proc. Natl. Acad. Sci. USA, 201614036.

Simmons, N. A., Forte, A. M., Boschi, L., Grand, S. P., 2010. GyPSuM: A joint tomographic model of mantle density and seismic wave speeds. J. Geophys. Res.115 (B12).

Stackhouse, S., Brodholt, J. P., Price, G. D., 2007. Electronic spin transitions in iron-bearing MgSiO3 perovskite. Earth Planet. Sci. Lett.253 (1), 282290.

Stixrude, L., Lithgow-Bertelloni, C., 2011. Thermodynamics of mantle minerals: II. Phase equilibria. Geophys. J. Int.184 (3), 1180-1213.

Stixrude, L., Lithgow-Bertelloni, C., Kiefer, B., Fumagalli, P., 2007. Phase stability and shear softening in $\mathrm{CaSiO} 3$ perovskite at high pressure. Phys. Rev.75 (2), 024108. 
Styles, E., Davies, D. R., Goes, S., 2011. Mapping spherical seismic into physical structure: biases from 3D phase-transition and thermal boundarylayer heterogeneity. Geophys. J. Int.184 (3), 1371-1378.

Su, W., Dziewonski, A., 1997. Simultaneous inversion for 3-D variations in shear and bulk velocity in the mantle. Phys. Earth Planet. Inter.100 (1-4), $135-156$

Tesoniero, A., Cammarano, F., Boschi, L., 2016. S- to- P heterogeneity ratio in the lower mantle and thermo-chemical implications. Geophys. Geochem. Geosys.17 (7), 2522-2538.

Trampert, J., Deschamps, F., Resovsky, J., Yuen, D., 2004. Probabilistic tomography maps chemical heterogeneities throughout the lower mantle. Science306 (5697), 853.

Tsuchiya, T., Tsuchiya, J., Umemoto, K., Wentzcovitch, R., 2004. Phase transition in MgSiO3 perovskite in the Earth's lower mantle. Earth Planet. Sci. Lett.224 (3-4), 241-248.

Wentzcovitch, R., Justo, J., Wu, Z., da SILVA, C. R., Yuen, D., Kohlstedt, D., 2009. Anomalous compressibility of ferropericlase throughout the iron spin cross-over. Proc. Natl. Acad. Sci. USA106 (21), 8447-8452.

Wessel, P., Smith, W. H. F., Scharroo, R., Luis, J., Wobbe, F., 2013. Generic mapping tools: Improved version released. Eos, Transactions American Geophysical Union 94 (45), 409-410.

Wookey, J., Stackhouse, S., Kendall, J.-M., Brodholt, J., Price, G. D., 2005. 
843 Efficacy of the post-perovskite phase as an explanation for lowermostmantle seismic properties. Nature438 (7070), 1004-1007.

Zaroli, C., Koelemeijer, P., Lambotte, S., 2017. Toward seeing the Earth's interior through unbiased tomographic glasses. Geophys. Res. Lett.44 (22). perovskite under lower mantle conditions and the composition of the deep Earth. Earth Planet. Sci. Lett.379, 1-12. 


\section{Figures}

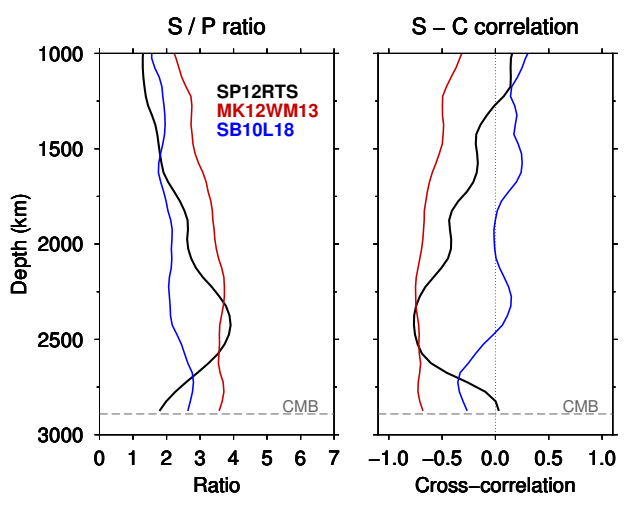

Figure 1: Characteristics of global tomography showing the S/P ratio (left) and S-C correlation (right) for some extreme cases: body-wave model MK12WM13 of Su and Dziewonski (1997) (red), long-period model SB10L18 of Masters et al. (2000) (blue) and mixed-data model SP12RTS of Koelemeijer et al. (2016) (black). 


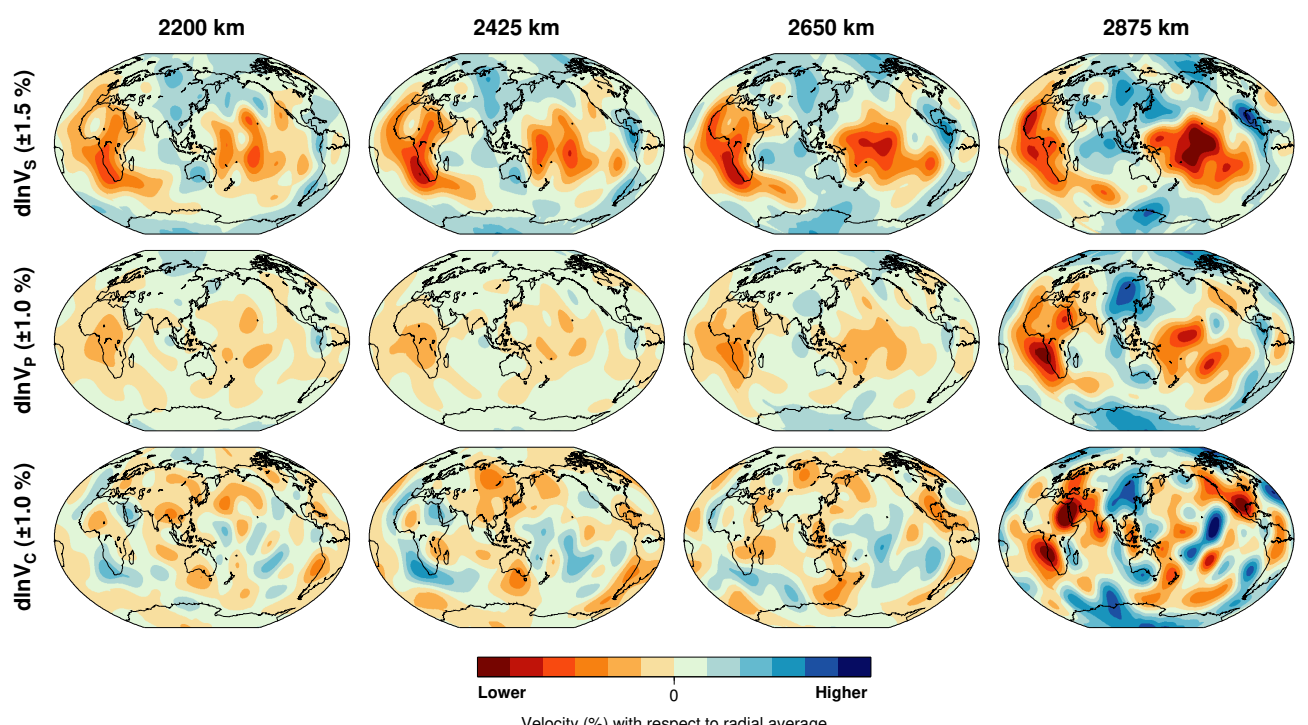

Figure 2: Variations in shear-wave velocity $\operatorname{d} \ln V_{S}$ (top), compressional-wave velocity $\operatorname{dn} \ln V_{P}$ (middle) and bulk-sound velocity $\operatorname{dn} V_{C}$ (bottom) according to model SP12RTS at different depths in the mantle. Velocity is higher (lower) than the radial average at each depth in blue (red) regions and the colour intensity is proportional to the velocity amplitude up to a maximum of $1.5 \%$ for $\operatorname{d} \ln V_{S}$ and $1.0 \%$ for $\operatorname{dn} V_{P}$ and $\operatorname{d} \ln V_{C}$, respectively. Note that $\operatorname{dln} V_{C}$ are constructed using $\operatorname{dnn} V_{S}$ and $\operatorname{d} \ln V_{P}$, thus giving rise to small-scale artefacts that should not be interpreted. 


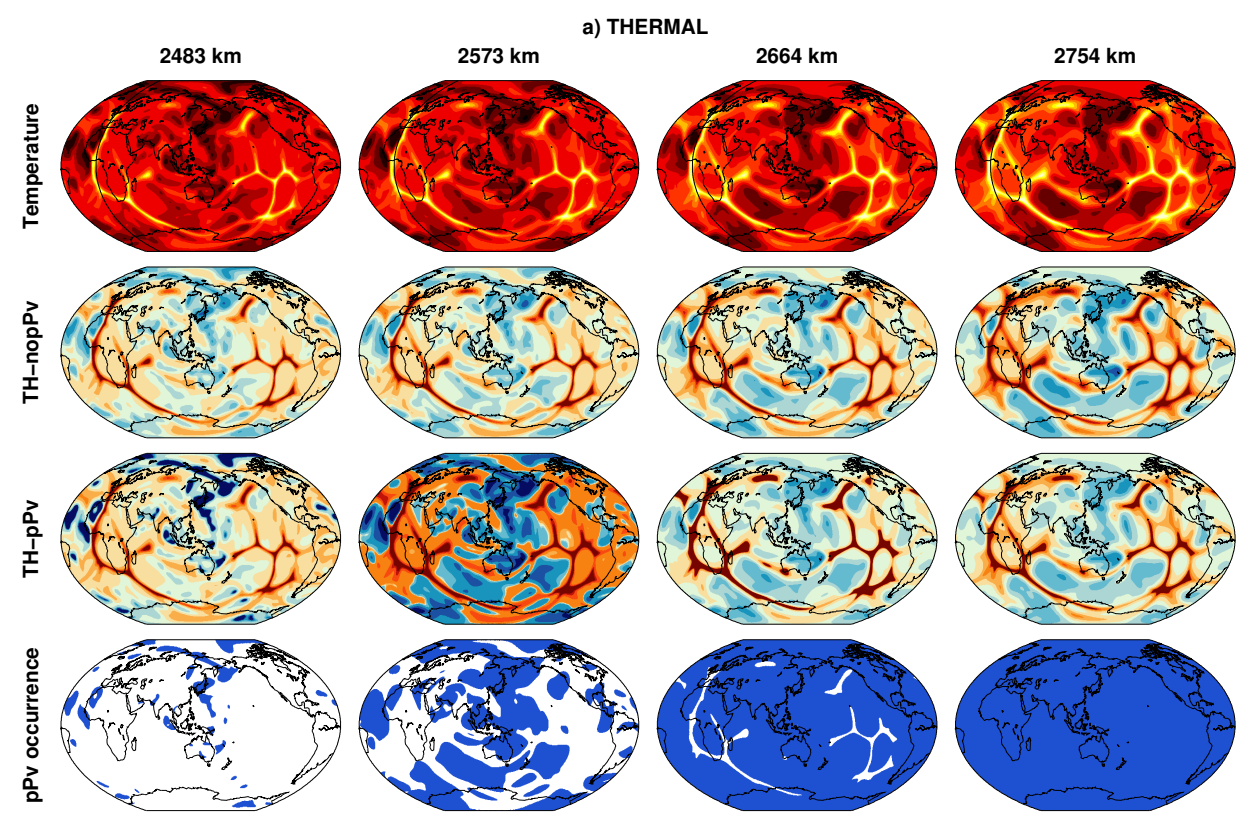

b) THERMOCHEMICAL
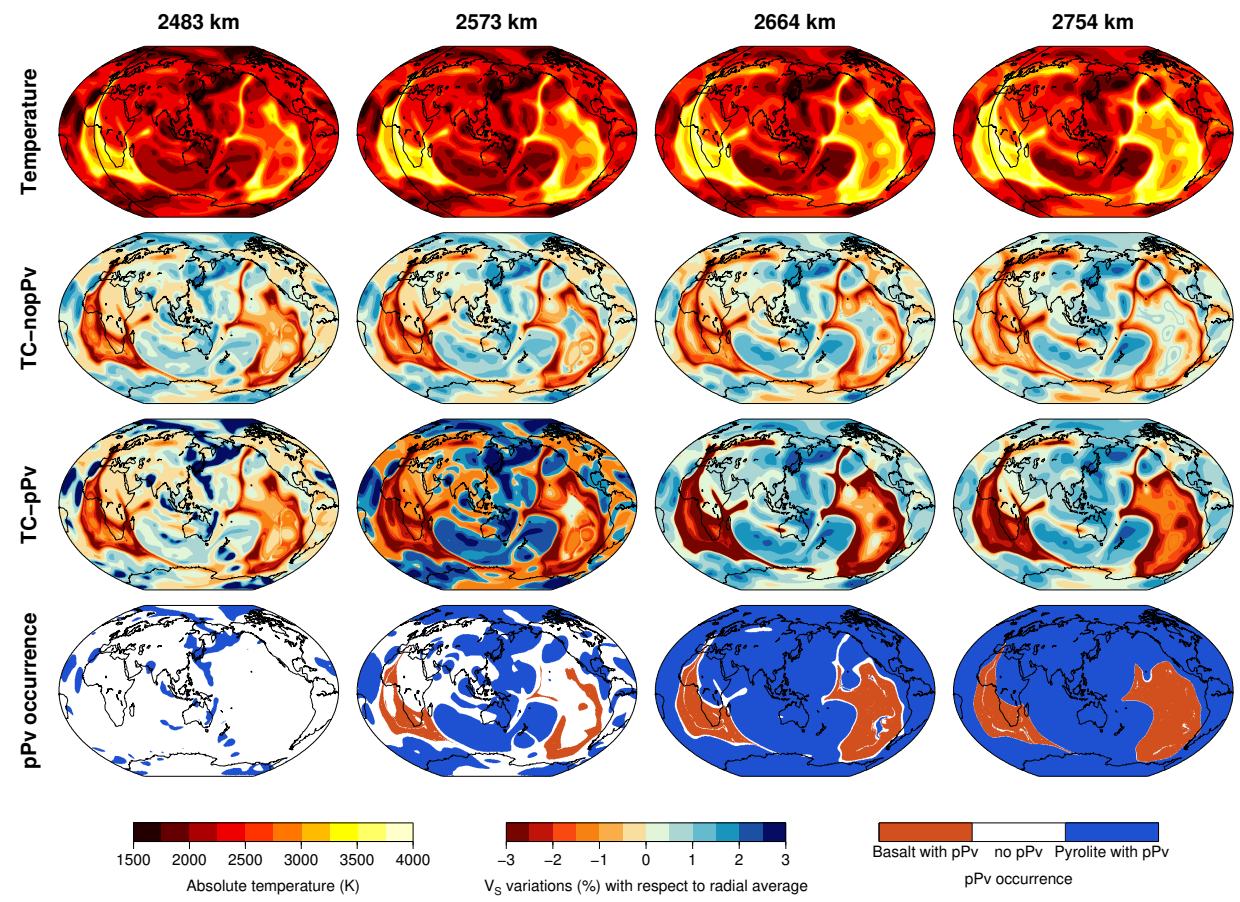

Figure 3: Temperature, shear-wave velocity variations and $\mathrm{pPv}$ occurrence maps for (a) thermal (TH) models and (b) thermochemical (TC) models at different depths in the lowermost mantle. In each case, the top row shows the absolute temperature field (generated by the geodynamic modelling), the middle rows show the $V_{S}$ structure (based on the mineral physics conversion) without and with $\mathrm{pPv}$ present, respectively, and the bottom row shows the lateral variations in $\mathrm{pPv}$ occurrence. For the shear-wave velocity variations, we remove the radial average at each depth. 


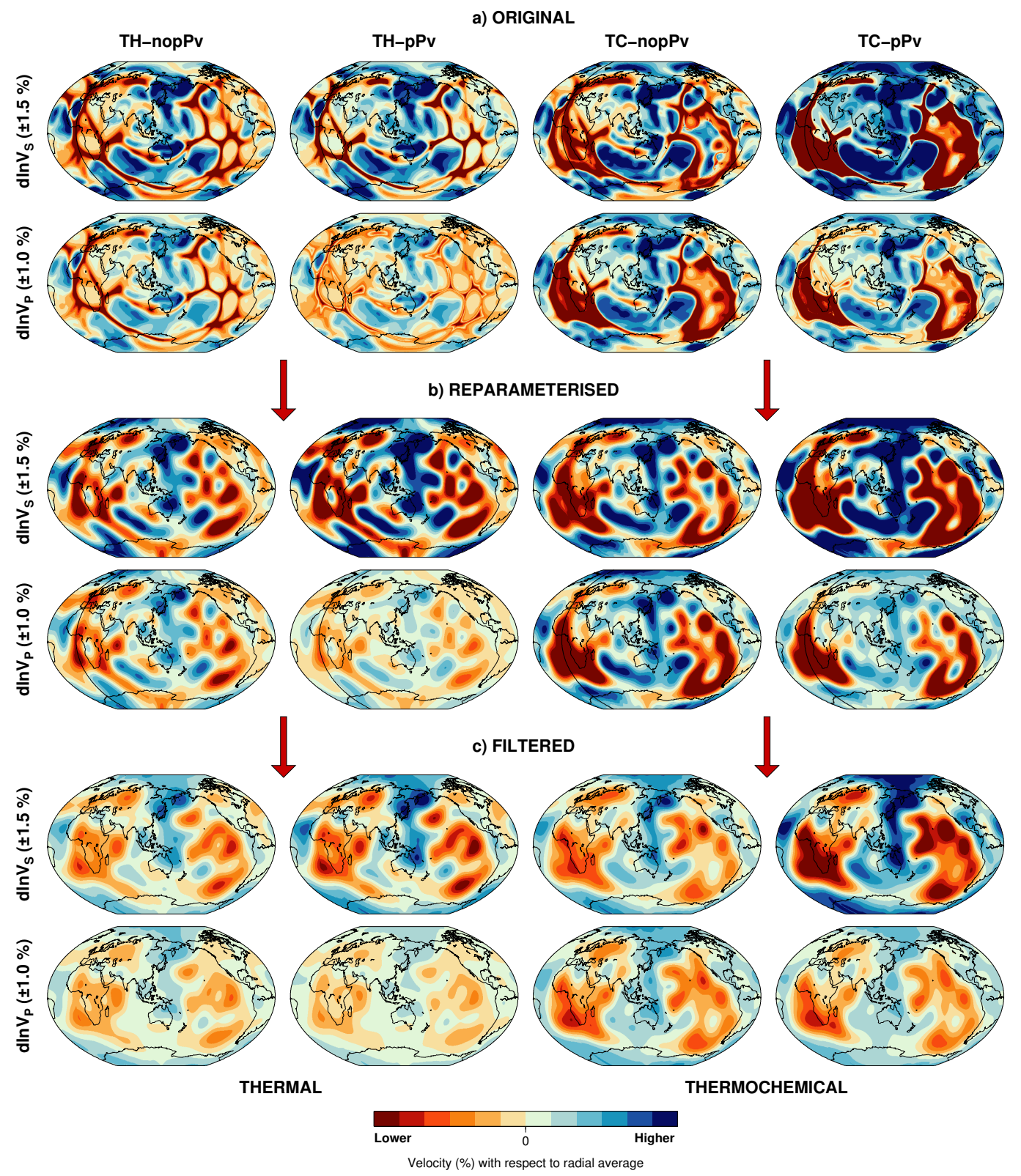

Figure 4: $\operatorname{dln} V_{S}$ (top) and $\operatorname{dnn} V_{P}$ (bottom) at $2650 \mathrm{~km}$ depth for (a) the original highresolution geodynamic models, (b) the reparameterised geodynamic models and (c) the tomographically filtered geodynamic models. The colour scale is the same as in Fig. 2 with a maximum amplitude of $1.5 \%$ for $\operatorname{dn} \ln V_{S}$ and $1.0 \%$ for $\operatorname{dn} V_{P}$. The reparameterisation affects $\operatorname{d} \ln V_{S}$ and $\operatorname{dn} V_{P}$ structures in a similar way. Subsequently, the multiplication with $\mathcal{R}$ decreases both fast and slow anomalies by $\sim 35-50 \%$, consistent with findings by (Zaroli et al., 2017). The effect of $\mathrm{pPv}$ remains evident after filtering, with models including $\mathrm{pPv}$ showing larger amplitudes for $\operatorname{d} \ln V_{S}$ and lower amplitudes for $\operatorname{d} \ln V_{P}$. 


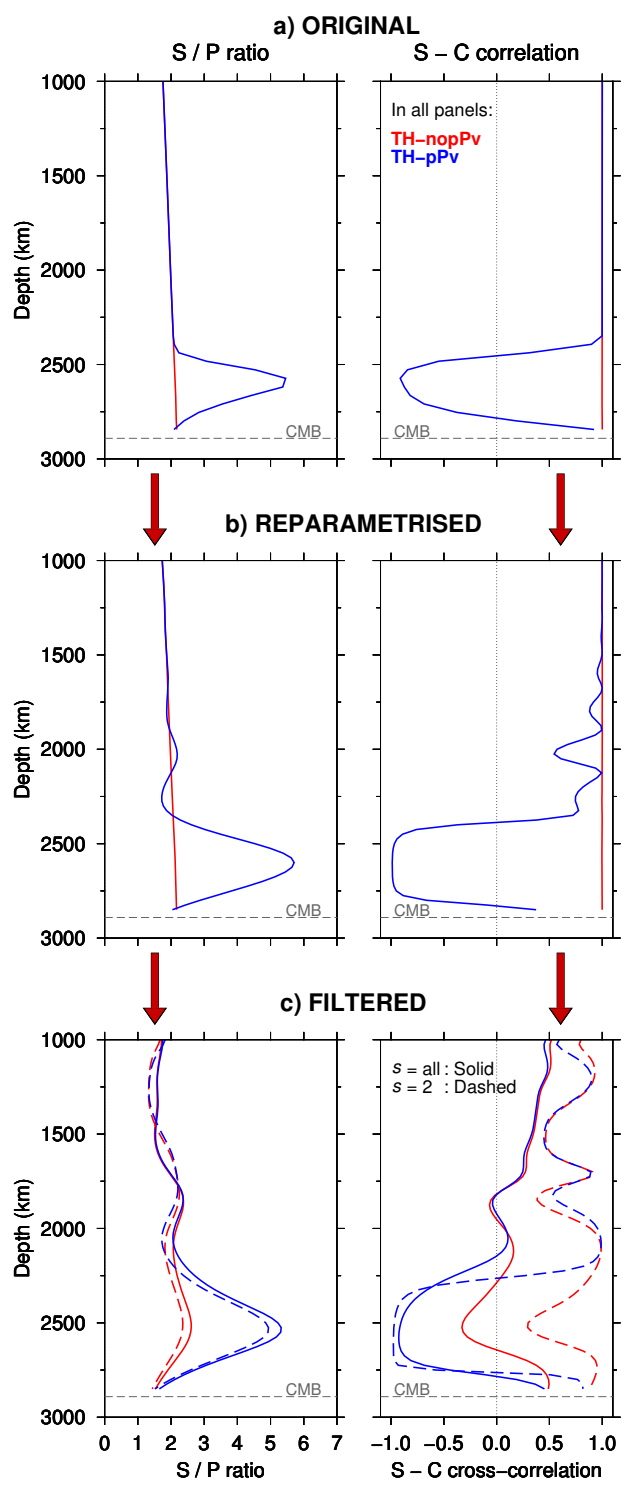

Figure 5: Effects of reparameterisation and tomographic filtering on the S/P ratio (left) and S-C correlation (right) for thermal (TH) models. (a) Original high-resolution geodynamic models, (b) reparameterised geodynamic models and (c) tomographically filtered geodynamic models. Red and blue lines show thermal models without $\mathrm{pPv}$ (TH-nopPv) and with $\mathrm{pPv}$ (TH-pPv), respectively, with dashed lines in (c) indicating the degree 2 component only. 


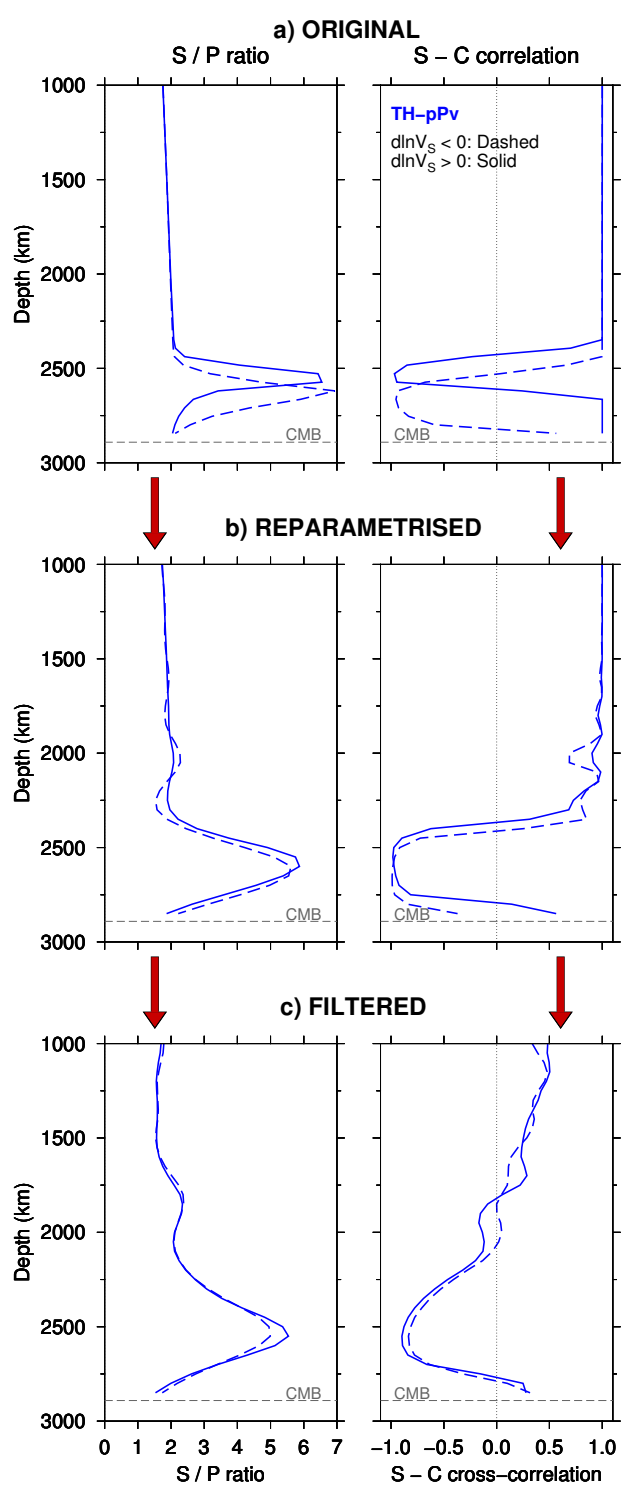

Figure 6: The S/P ratio (left) and S-C correlation (right) in thermal model TH-pPv with post-perovskite present, separated into regions of fast (solid) and slow (dashed) shear-wave velocity variations. (a) Original high-resolution, (b) reparameterised, and (c) tomographically filtered geodynamic models. 


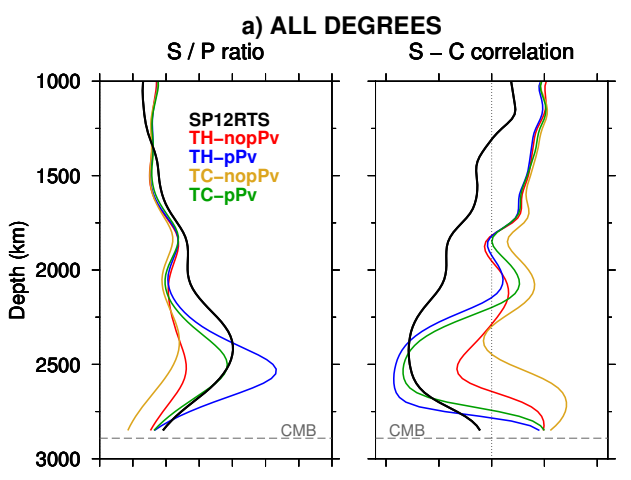

b) $s=2$ ONLY

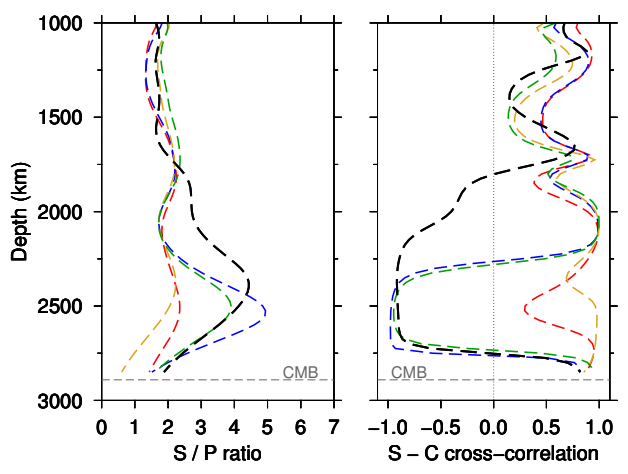

Figure 7: Comparison of the $\mathrm{S} / \mathrm{P}$ ratio (left) and $\mathrm{S}-\mathrm{C}$ correlation (right) between the geodynamic models and SP12RTS for (a) all spherical harmonic degrees up to $s=12$ and (b) degree $s=2$ only (dashed lines). Black lines show the characteristics of SP12RTS, whereas different colours represent the geodynamic models, as indicated in the figure. 


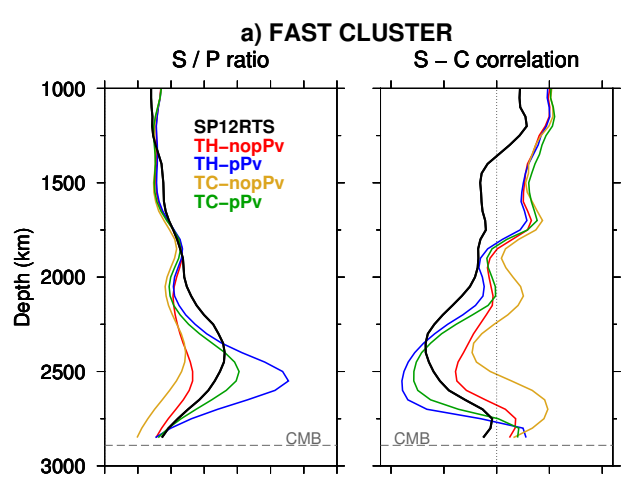

b) SLOW CLUSTER

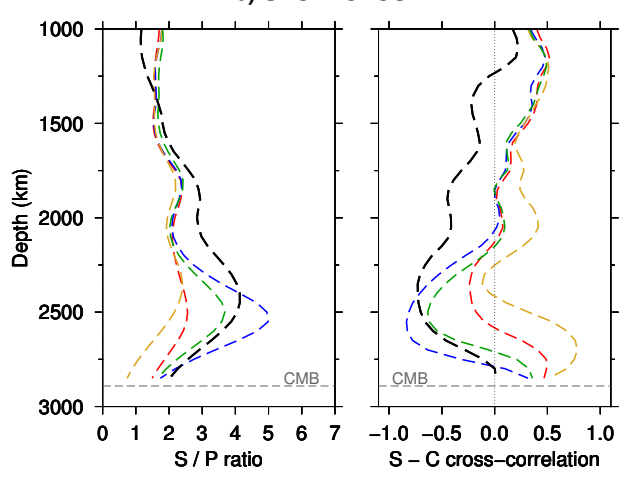

Figure 8: Comparison of the $\mathrm{S} / \mathrm{P}$ ratio (left) and S-C correlation (right) calculated for (a) the fast cluster and (b) the slow cluster for all geodynamic models and SP12RTS. Colours are the same as in Fig. 7. 


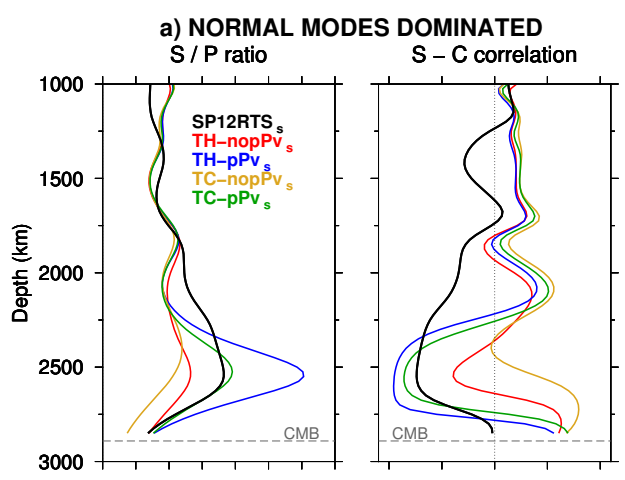

b) BODY WAVES DOMINATED

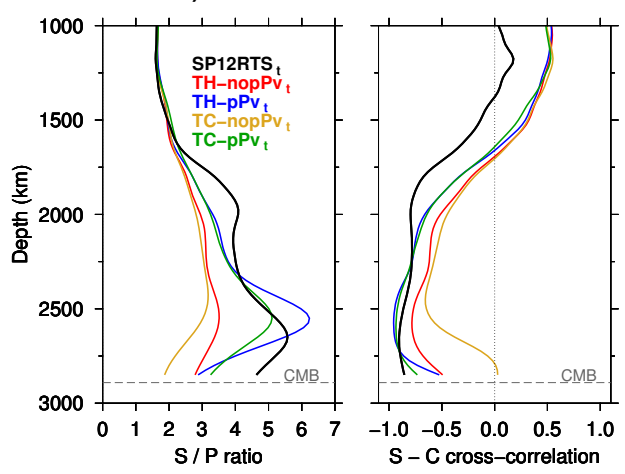

Figure 9: Comparison of the S/P ratio (left) and S-C correlation (right) between geodynamic models and tomographic models obtained with different data weighting (i.e. $\mathrm{SP}^{2} \mathrm{RTS}_{s}$ and SP12RTS $t$ for inversions dominated by normal-mode and body-wave data, respectively), calculated for all spherical harmonic degrees. (a) Normal-mode data dominated inversion. (b) Body-wave data dominated inversion. The same colours as in Fig. 7 represent the geodynamic models, but we now filter them using either (a) $\mathcal{R}_{s}$ or (b) $\mathcal{R}_{t}$. 

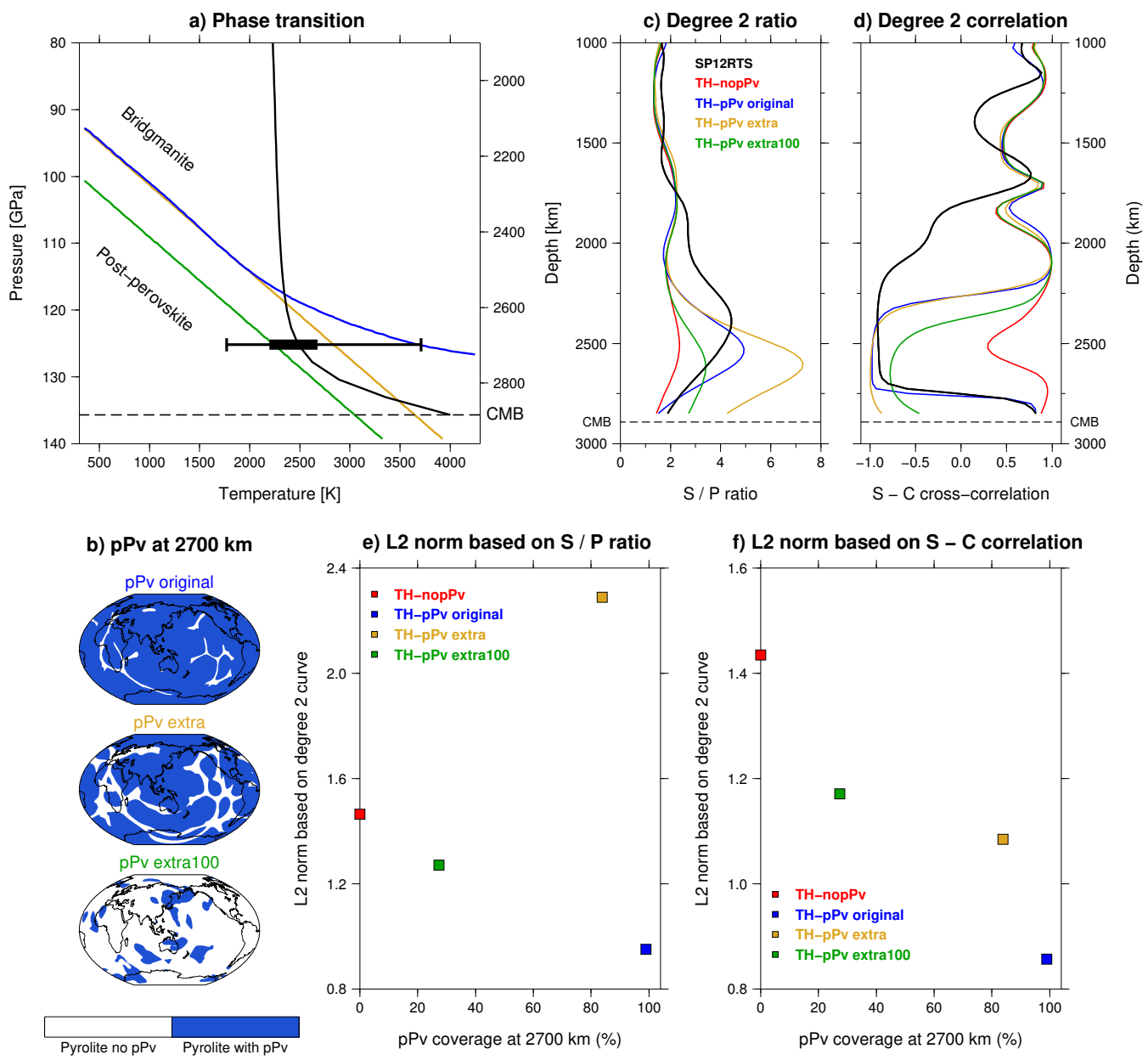

Figure 10: Effect of (a) different Clapeyron slopes of the phase transition in pyrolite on (b) the amount of $\mathrm{pPv}$ in the lower mantle, (c) the $\mathrm{S} / \mathrm{P}$ ratio and (d) the $\mathrm{S}-\mathrm{C}$ correlation. (e) and (f) show the L2 norm between SP12RTS and the geodynamic models, based on the degree-2 curves of either (e) the S/P ratio or (f) the S-C correlation. The black line in (a) gives the geotherm of the TH model and the boxcar indicates the 1, 25, 75 and $99 \%$ percentiles of the temperature distribution at $2700 \mathrm{~km}$ depth. The resulting $\mathrm{pPv}$ occurrence maps in (b) contain either pPv everywhere at the CMB for the original mineral physics table (blue) or contain $\mathrm{pPv}$ lenses in the colder regions for the extrapolated tables "extra" (yellow) and "extra100" (green). The patterns in the S/P ratio (c) and S-C correlation (d) curves for degree 2 of SP12RTS (black) are matched best by the original mineral physics table (blue). 